\title{
əoverturning Response to a Surface Wind Stress Doubling in an Eddying and a Non- Eddying Ocean
}

\author{
VeIt LÜSCHOW, ${ }^{\mathrm{a}, \mathrm{b}}$ JoChem MAROTZKE, ${ }^{\mathrm{a}, \mathrm{c}}$ AND JIN-SONG VON STORCH ${ }^{\mathrm{a}, \mathrm{c}}$ \\ ${ }^{a}$ Max Planck Institute for Meteorology, Hamburg, Germany \\ ${ }^{\mathrm{b}}$ International Max Planck Research School on Earth System Modelling, Hamburg, Germany \\ ${ }^{\mathrm{c}}$ Center for Earth System Research and Sustainability (CEN), Universität Hamburg, Hamburg, Germany
}

(Manuscript received 29 July 2020, in final form 22 December 2020)

\begin{abstract}
In this paper, the overturning responses to wind stress changes of an eddying ocean and a non-eddying ocean are compared. Differences are found in the deep overturning cell in the low-latitude North Atlantic Ocean with substantial implications for the deep western boundary current (DWBC). In an ocean-only twin experiment with one eddying and one non-eddying configuration of the MPI ocean model, two different forcings are being applied: the standard NCEP forcing and the NCEP forcing with $2 \times$ surface wind stress. The response to the wind stress doubling in the Atlantic meridional overturning circulation is similar in the eddying and the non-eddying configuration, showing an increase by about $4 \mathrm{~Sv}(\sim 25 \% ; 1 \mathrm{~Sv} \equiv$ $\left.10^{6} \mathrm{~m}^{3} \mathrm{~s}^{-1}\right)$. In contrast, the DWBC responds with a speedup in the non-eddying configuration and a slowdown in the eddying configuration. This paper demonstrates that the DWBC slowdown in the eddying configuration is largely balanced by eddy vorticity fluxes. Because those fluxes are not resolved and also not captured by an eddy parameterization in the non-eddying configuration, such a DWBC slowdown is likely not to occur in non-eddying ocean models, which therefore might not capture the whole range of overturning responses. Furthermore, evidence is provided that the balancing effect of the eddies is not a passive reaction to a remotely triggered DWBC slowdown. Instead, deep eddies that are sourced from the upper ocean provide an excess input of relative vorticity that then actively forces the DWBC mean flow to slow down.
\end{abstract}

KEYWORDS: Eddies; Meridional overturning circulation; Mesoscale processes; Ocean dynamics; Wind stress

\section{Introduction}

Modifications to Earth's surface wind field due to climate change have been observed (Thompson and Solomon 2002; Marshall 2003; Rintoul 2018), and further changes are likely in the future (e.g., Bracegirdle et al. 2013; Gillett and Fyfe 2013; Farneti et al. 2015). In particular for the Southern Ocean westerlies, which are anticipated to strengthen and shift southward, we expect these changes to have considerable influence on the ocean mean state. The strength and shape of the Atlantic meridional overturning circulation (AMOC), which is responsible for large parts of the global oceanic meridional heat transport, might be significantly affected by changes in the Southern Ocean winds. A detailed understanding of the AMOC response to surface wind changes is required in the light of climate change.

Previous studies about the overturning's wind sensitivity mostly focused on the direct response of the upper overturning cell, which we usually refer to as AMOC cell. It was expected to strengthen linearly with increasing Southern Ocean wind stress ("Drake passage effect"; Toggweiler and Samuels 1995, 1998) until Henning and Vallis (2005) and Hallberg and Gnanadesikan (2006) detected a reduction in the overturning wind sensitivity when switching from non-eddying to more realistic

\footnotetext{
¿ Denotes content that is immediately available upon publication as open access.
}

Corresponding author: Veit Lüschow, veit.lueschow@mpimet. mpg.de eddy-permitting ocean models [see Gent (2016) for a review on this process, named "eddy compensation"]. Nevertheless, the vital role of the wind stress in controlling the Southern Ocean pathway for dense water toward the surface and thus its role for the AMOC remains undisputed (Marshall and Speer 2012).

Besides this direct link between wind stress and AMOC, the concept of the "ocean seesaw" (Broecker 1998) provides a possible second, indirect link. Patara and Böning (2014) recently demonstrated how a weakening of the bottom overturning cell induced by reduced Antarctic bottom water (AABW) formation may lead to a stronger upper AMOC cell. While the AABW reduction in their experiment was initiated by perturbations in the Southern Ocean buoyancy, AABW formation can also be influenced by Southern Ocean winds (e.g., Brix and Gerdes 2003; Poulsen et al. 2018). Hence, the ocean seesaw opens up a second route for the Southern Ocean wind stress to affect the AMOC strength.

In this paper, we present wind sensitivity experiments conducted with one eddying and one non-eddying configuration of the same realistic-geometry Max Planck Institute ocean model (MPIOM). It turns out that the response to a wind stress doubling is a seesaw characterized by a strengthening of the upper (AMOC) cell and a weakening of the bottom (AABW) cell in both configurations. However, the extent of the bottom-cell weakening differs strongly between the two configurations. This also implies a response difference of the DWBC, which comprises both the lower limb of the AMOC cell and the upper limb of the bottom cell. Therefore, a more detailed inspection of the deep circulation response and the role of eddies there is needed. As far as we know, this deep response has not yet been studied in eddy-resolving setups and so it will be investigated here. 
Based on the described outcome of our sensitivity experiments, we formulate the following guiding research questions: (i) Can we relate the response differences in the DWBC to whether eddies are resolved or not? (ii) And if yes, what are the implications for our understanding of the ocean seesaw in the real (eddying) ocean? By answering these questions, we provide a new perspective on what role mesoscale eddies may play for the AMOC response to forcing changes: besides dampening the above discussed direct impact of Southern Ocean wind stress on AMOC (eddy compensation), eddies might also control the response of the DWBC to forcing changes and in doing so exert an indirect control over the overturning response.

The design of our wind sensitivity experiment is not guided by the most likely future state of the wind field. We choose to double the wind stress in order to provoke a large signal in the ocean response. Our aim is rather to gain a conceptual understanding of the processes involved than to quantify the actual strength of the overturning response to changes in the surface winds. Because of the high computational costs of the STORM configuration, we could run the sensitivity experiments for only 31 years from 1980 to 2010, and thus we will focus on the decadal scale response. Nevertheless, we find significant modifications of the ocean mean state within that period and thus consider our results meaningful. Other high-resolution sensitivity studies analyze simulations of comparable length (e.g., Bishop et al. 2016; Hogg et al. 2017; Poulsen et al. 2018).

The paper begins with a description of our experimental setup (section 2), before illustrating the quasi-steady-state overturning response. It shows a substantial DWBC slowdown in the eddying STORM configuration (section 3). In section 4, we show that a link exists between this DWBC slowdown and eddy vorticity fluxes (EVF). We then analyze in detail the evolution of the response signal and suggest a potential response mechanism that caused the DWBC slowdown (section 5). Section 6 contains a discussion and conclusions.

\section{Experiment design}

We use two different configurations of the global ocean model MPIOM. One was developed within the German consortium project STORM with a tripolar grid at $0.1^{\circ}$ horizontal resolution (hereinafter STORM), which we assume to be $e d$ dying. The other is a standard MPIOM version and utilizes a bipolar grid with an effective resolution of about $1.5^{\circ}$ (hereinafter GR15), which we assume to be non-eddying. Driving each model configuration (eddying and non-eddying) with three different surface wind stress scenarios enables us to test whether the ocean's response to changes in the surface wind stress depends on whether mesoscale eddies are resolved.

In the control scenario, we apply the standard NCEPNCAR Reanalysis-1 forcing (Kalnay et al. 1996) and run it from 1948 to 2010, after a 25-yr spinup with Ocean Model Intercomparison Project (OMIP) forcing (Röske 2006). These runs will be referred to as S1X for the eddying STORM and G1X for the non-eddying GR15 configuration. Note also the gray table in Fig. 1 for the experiment labeling. Two sensitivity scenarios are branched off in the year 1980: In the first one, we double the zonal and meridional wind stress by adding their

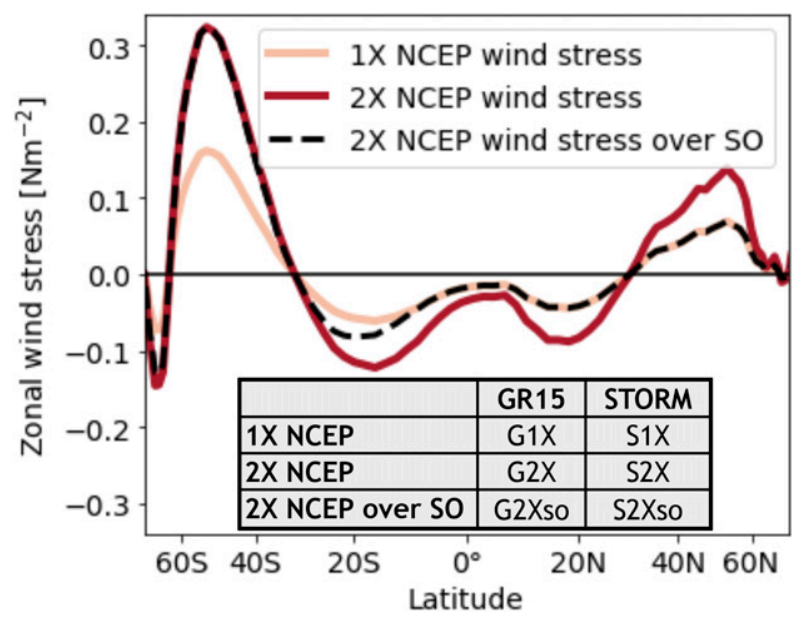

FIG. 1. Three different zonal mean zonal wind stress fields that we use for this paper, averaged in the period between 1948 and 2016: standard NCEP wind stress (1X NCEP; light red), doubled NCEP wind stress (2X NCEP; dark red), and NCEP wind stress doubled only over the Southern Ocean (2X NCEP over SO; dashed black). The gray table gives an overview over the experiments that we ran ( 3 different wind stresses $\times 2$ different model configurations $=6$ experiments).

monthly climatology to the original NCEP wind stress (experiments referred to as S2X for STORM and G2X for GR15; Fig. 1). In the second sensitivity scenario, we double the wind stress only over the Southern Ocean by adding to the standard NCEP wind stress the monthly climatology multiplied by a sine function. This sine function is centered around the maximum negative wind stress at $48^{\circ} \mathrm{S}$ and declines to zero at the equator and at the South Pole (S2Xso for STORM and G2Xso for GR15; Fig. 1). Although not strictly oriented at anticipated future wind stress conditions, the second scenario is more realistic than the first one.

Thus, in total we analyze six different experiments, three of which resolve mesoscale eddies (S1X, S2X, and S2Xso) and three that do not (G1X, G2X, and G2Xso). Running one set of experiments with winds enhanced globally and one set with winds enhanced only over the Southern Ocean makes it possible to distinguish between local and remote wind effects. However, the quasi-steady-state response in the mean AMOC and DWBC transport as well as their vertical response structure is quite similar in the experiments S2X and S2Xso on the one hand as well as G2X and G2Xso on the other hand. Therefore, in this paper we mainly focus on the two scenarios S2X and G2X with globally doubled wind stress.

The STORM configuration with its tripolar grid has two coordinate poles in the Northern Hemisphere over Asia and North America, ensuring an essentially uniform resolution. STORM's ability to represent large parts of the mesoscale eddy field was demonstrated for mesoscale eddies in general (e.g., von Storch et al. 2012; Li and von Storch 2013; von Storch et al. 2016) and also for deep eddies in particular (Lüschow et al. 2019). The GR15 configuration uses a bipolar grid with a resolution of about $180 \mathrm{~km}$ in our region of interest at low latitudes, rendering it mostly free of eddies. Consequently, the Gent-McWilliams eddy parameterization (Gent et al. 1995) is switched off in STORM while switched 


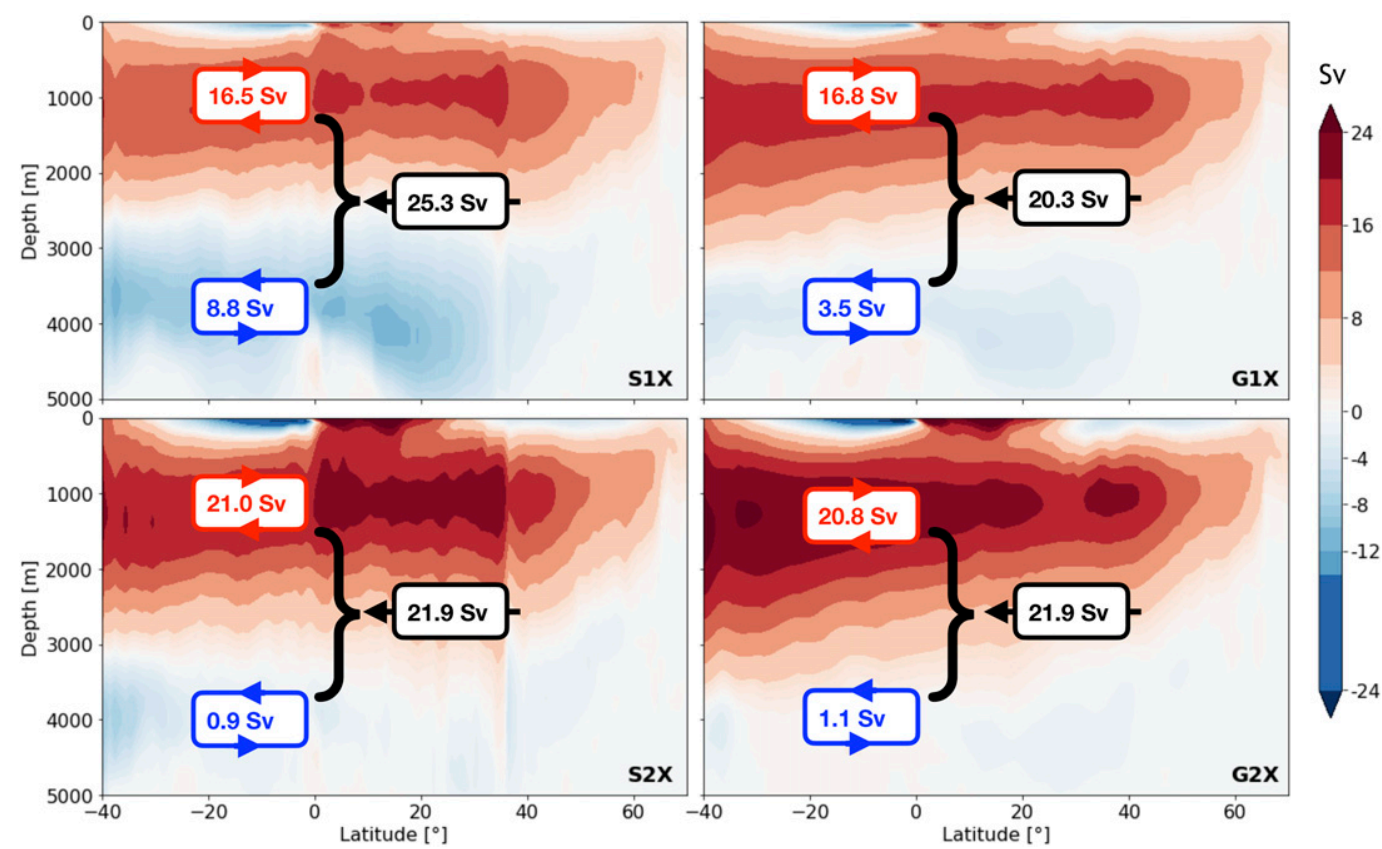

FIG. 2. AMOC streamfunctions for the four experiments with standard NCEP wind stress (top left) S1X and (top right) G1X and with doubled NCEP wind stress (bottom left) S2X and (bottom right) G2X. Streamfunctions are computed from data averaged between 2001 and 2010. Red numbers and arrows belong to the upper (AMOC) overturning cell. They are diagnosed at $1000-\mathrm{m}$ depth and averaged between $5^{\circ}$ and $20^{\circ} \mathrm{N}$. Blue numbers and arrows belong to the bottom (AABW) cell, diagnosed at 4000-m depth and likewise averaged between $5^{\circ}$ and $20^{\circ} \mathrm{N}$. Black numbers and arrows show the total southward DWBC transport.

on in GR15. The strength of the parameterization in GR15 is controlled via the Gent-McWilliams thickness diffusivity that is defined as a value scaled with the grid size in MPIOM. In these experiments, we use the GR15 standard of $94 \mathrm{~m}^{2} \mathrm{~s}^{-1}$ per $100 \mathrm{~km}$ grid size. Thus, the parameterized effect of mesoscale eddies in the GR15 runs is negligibly small (von Storch et al. 2016). A discussion of the role of the magnitude of the thickness diffusivity for the outcome of our sensitivity experiments can be found in appendix A. Both configurations have 80 vertical levels that range from 10 $\mathrm{m}$ level thickness at the surface to about $250 \mathrm{~m}$ at the ocean bottom. Furthermore, both configurations are coupled to a sea ice model that includes the thermodynamics and dynamics of sea ice as well as sea ice growth and melt implying brine injection. The surface freshwater forcing is a net of precipitation provided by the NCEP-NCAR reanalysis, the OMIP river runoff, and evaporation derived from latent heat flux. Additionally, we apply at the surface a salinity restoring with a time scale of 35 days. Latent and sensible heat fluxes are computed using bulk formula (Marsland et al. 2003). Further model details as well as more results inferred from the STORM configuration of MPIOM can be found in von Storch et al. (2012, 2016). Details on the GR15 configuration are available in Jungclaus et al. (2006, 2013).

\section{Quasi-steady-state overturning response to the wind stress doubling}

The eddying STORM and the non-eddying GR15 configuration both show signatures of the ocean seesaw with a strengthening of the upper (AMOC) and a weakening of the bottom $(\mathrm{AABW})$ overturning cell as response to the wind stress doubling. In this section, we portray the quasi steady state of this response, in which the AMOC and AABW transports stay relatively constant. The quasi-steady-state response arises after about 15-20 years and lasts for at least the last 10 years of the simulation from 2001 to 2010. As mentioned in the introduction, running a longer simulation was not feasible for us with the STORM configuration because of its high computational costs. However, we extended for the noneddying GR15 configuration the control run (G1X) as well as the run with globally doubled wind stress (G2X) until 2110. After 2010, we applied in cycles of 30 years the forcing that we used between 1980 and 2010 in G1X and G2X, respectively. It turns out that the overturning response does not change qualitatively after 2010 and furthermore that the largest part of the total response that we see until 2110 indeed occurs in the first 30 years between 1980 and 2010 (see appendix B for a time series of the extended run as well as a more detailed discussing on the length of the experiments). Our conclusion is that the chosen period between 2001 and 2010 is meaningful for the non-eddying GR15 configuration and based on this, we assume that the same is largely true also for the eddying STORM configuration. For the remainder of this and the next section, we use data that were time averaged between 2001 and 2010 .

Figure 2 visualizes the overturning streamfunctions for this period; numbers indicate the transport averaged between $5^{\circ}$ and $20^{\circ} \mathrm{N}$ in the upper (AMOC) cell and the bottom (AABW) 

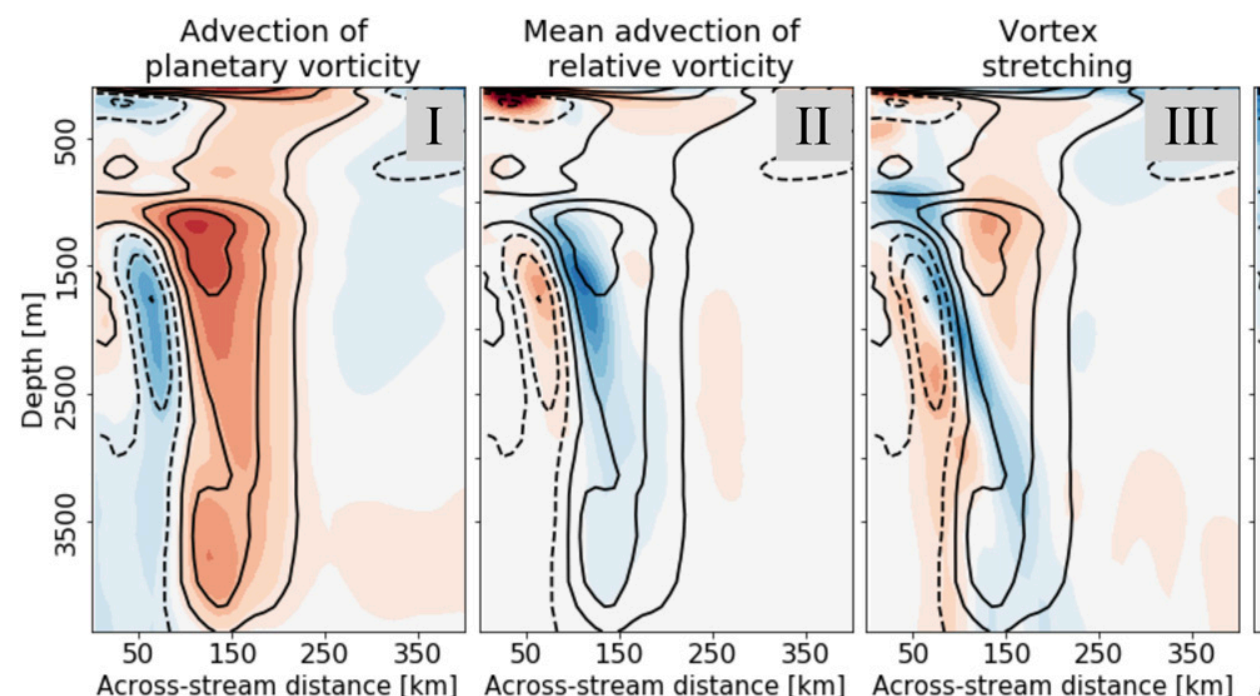

\section{Eddy vorticity flux convergence}

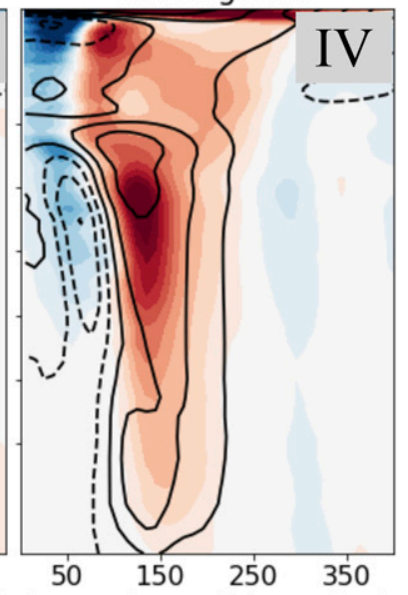

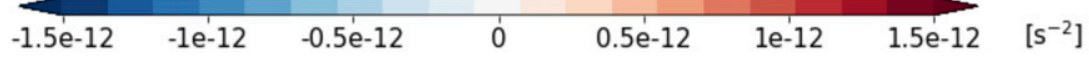

FIG. 3. Response S2X-S1X (see text) to global wind stress doubling in the DWBC vorticity budget in the order in which they appear in Eq. (4) in a depth-vs-across-stream view. Color shadings show the (left) advection of planetary vorticity (term I), (left center) mean advection of relative vorticity (term II), (right center) vortex stretching (term III), and (right) EVF convergence (term IV). For comparison, black contour lines show the advection of planetary vorticity from term I (the left panel) with a contour interval of $1.5 \times$ $10^{-13}$. The dominant balance is between terms I and IV, whereas II and III have the wrong sign, magnitude, and pattern to balance I. All data are time averaged (2001-10) and averaged along the DWBC path $\left(20^{\circ}-5^{\circ} \mathrm{N}\right)$, and we apply a Gaussian filter in the acrossstream direction with a half-width of $10 \mathrm{~km}$. The $x$ axis shows the across-stream distance from the continental shelf. The " $\mathrm{e}$ " in the units of the color shading here and in subsequent figures indicates that the preceding number should be multiplied by 10 raised to the following sign and number.

cell, as well as the DWBC transport. AMOC's quasi-steadystate response is characterized by a $25 \%$ increase in G2X and S2X. Both configurations also share a weakening of the AABW cell. Yet, we find significant differences in the extent of this weakening. In the following, we will see that this has consequences for the DWBC.

Doubling the wind stress leads to an increase in the northward surface transport of about $4.5 \mathrm{~Sv}\left(1 \mathrm{~Sv} \equiv 10^{6} \mathrm{~m}^{3} \mathrm{~s}^{-1}\right)$ in STORM and 4.0 Sv in GR15. Necessarily, the southward return flow of North Atlantic Deep Water (NADW) has to increase, too. However, the relatively strong AABW cell in S1X $(8.8 \mathrm{~Sv})$ significantly weakens in $\mathrm{S} 2 \mathrm{X}(0.9 \mathrm{~Sv})$. This means that, although the upper overturning cell strengthens when the wind stress is doubled, the DWBC transport, consisting of NADW from the upper cell and AABW from the lower cell, decreases from S1X $(25.3 \mathrm{~Sv})$ to $\mathrm{S} 2 \mathrm{X}(21.9 \mathrm{~Sv})$. The bottom cell in G1X is already comparatively weak ( $3.5 \mathrm{~Sv})$, and it further decreases in G2X (1.1 Sv). Nevertheless, this implies a net increase in the DWBC transport from G1X (20.3 Sv) to G2X (21.9 Sv). In addition to different response signs in S2X and G2X, the DWBC response magnitude differs by a factor of $2(-3.4 \mathrm{~Sv}$ in $\mathrm{S} 2 \mathrm{X}$ and $+1.6 \mathrm{~Sv}$ in G2X). We want to note that the AMOC streamfunctions shown in Fig. 2 represent the zonally averaged flow and not necessarily the boundary flow such as the DWBC. However, zonal sections of the meridional flow show that the described changes in the AMOC streamfunctions originate in changes in the boundary flow. This means that the DWBC slows down in the eddying S2X (see also the left panel in Fig. 3) and speeds $u p$ in the non-eddying G2X (not shown).

The response difference between STORM and GR15 might be caused entirely by their different basic states. In particular, the bottom overturning cell in S1X is more than twice as strong as in G1X (see Fig. 2). To get a better understanding of what role the basic state plays for the response, we conduct two more runs with the non-eddying GR15 configuration that we call G1X* and G2X*. In the new runs, we increase the surface salinity restoring south of $65^{\circ} \mathrm{S}$ by $1 \mathrm{psu}$. In agreement with Brix and Gerdes (2003), such a tuning leads to more AABW formation and hence a stronger bottom overturning cell without significantly affecting the upper cell; G1X* now shows $4.9-\mathrm{Sv}$ bottom overturning, whereas G2X* has $1.5 \mathrm{~Sv}$. The response of the bottom cell in $\mathrm{G} 2 \mathrm{X}^{*}(-3.4 \mathrm{~Sv})$ is of similar magnitude as in $\mathrm{G} 2 \mathrm{X}(-2.4 \mathrm{~Sv})$ but is significantly lower than in S2X $(-7.9 \mathrm{~Sv})$. Also, analogous to G2X, the DWBC in G2X* speeds up as compared with the control run G1X*. Despite the tuning, the bottom cell in $\mathrm{G} \mathrm{X}^{*}$ is still significantly weaker than in S1X. Nonetheless, the similarity in the response of G2X and G2X* together with the fact that they both differ considerably from S2X suggests that the basic state is less important than the question if eddies are resolved or not. In the next section, we will provide further evidence for the resolution dependence of the response by showing that a link exists between the DWBC slowdown in the STORM configuration and mesoscale eddy fluxes. 


\section{Quasi-steady-state response: DWBC slowdown and eddies in the STORM configuration}

Rhines and Holland (1979) and Holland and Rhines (1980) provide one of the first detailed descriptions of how mesoscale eddy fluxes can drive a mean flow. In their two-layer quasigeostrophic model, eddy potential vorticity fluxes $\overline{\mathbf{u}^{\prime} q^{\prime}}$ drive a flow $\overline{\mathbf{u}}$ via the time-averaged potential vorticity equation, $\overline{\mathbf{u}} \cdot \nabla \bar{q}=-\nabla \cdot\left(\overline{\mathbf{u}^{\prime} q^{\prime}}\right)$. In this equation and hereinafter, primed quantities denote temporal fluctuations that arise due to mesoscale eddies and overbars indicate mean fields, $q$ is potential vorticity. Van Sebille et al. (2012) only recently used a highresolution primitive equation ocean model to link the pathway of the eastward going branch of the DWBC to upper ocean eddies (the famous Agulhas rings). Like in Rhines and Holland (1979) and Holland and Rhines (1980), this link functions via eddy potential vorticity fluxes and now a $3 \mathrm{D}$ version of the mentioned potential vorticity equation.

Within the quasigeostrophic framework that applies to the boundary current setting we are interested in, the eddy potential vorticity flux $\overline{\mathbf{u}^{\prime} q^{\prime}}$ consists of two parts: On the one hand, we have the EVF, $\overline{\mathbf{u}^{\prime} \zeta^{\prime}}$, where $\zeta=\partial v / \partial x-\partial u / \partial y$ is the $z$ component of the relative vorticity. The EVF roots in the Reynolds-averaged momentum equation. On the other hand, we have the eddy thickness flux (ETF), $\partial\left(f \overline{\overline{\mathbf{u}}^{\prime} \rho^{\prime}} / \bar{\rho}_{z}\right) / \partial z$, that contains eddy fluxes of density $\rho$ (e.g., Olbers et al. 2012). In both of the examples mentioned earlier, eddies are primarily generated in the upper ocean (the upper layer, respectively) and drive, via the ETF component, a mean flow $\overline{\mathbf{u}}$ in the layer underneath (Holland and Rhines 1980; Van Sebille et al. 2012). In contrast, the EVF component is considered less important in both cases. However, Spall (1994) speculates that also the EVF might play a significant role near the DWBC.

\section{a. Eddy vorticity fluxes and DWBC slowdown}

By analyzing the response vorticity budget of the eddying STORM configuration, we now show that the DWBC slowdown is indeed closely linked to the EVF. Our starting point is the Reynolds-averaged, quasigeostrophic version of the vorticity equation

$$
\frac{D_{H}}{D t}(\bar{\zeta}+\beta y)=f \frac{\partial \bar{w}}{\partial z}-\nabla_{H} \cdot \overline{\mathbf{u}^{\prime} \zeta^{\prime}}
$$

(e.g., Olbers et al. 2012), where $\beta=\partial f / \partial y$ is the meridional gradient of the Coriolis parameter $f$. We describe the vertical velocity by $w$; the material derivative $D_{H} / D t=\partial / \partial t+\bar{u} \partial / \partial x+\bar{v} \partial / \partial y$ contains only the horizontal advection by the mean flow. Furthermore, we transform Eq. (1) into an along/across-stream coordinate system in which one horizontal axis points into the negative along-stream direction $x_{\|}\left(x_{\|}\right.$is directed approximately northward) and the other in the across-stream direction $x_{\perp}\left(x_{\perp}\right.$ is directed approximately westward toward the shore). Averaging along the DWBC (in the $x_{\|}$direction) from $20^{\circ}$ to $5^{\circ} \mathrm{N}$ and after some rearrangement, we are left with

$$
\begin{aligned}
& \left\langle\beta \bar{u}_{\|} \sin \alpha\right\rangle+\left\langle\beta \bar{u}_{\perp} \cos \alpha\right\rangle \\
& =-\left\langle\overline{\mathbf{u}}_{H} \cdot \nabla_{H} \bar{\zeta}\right\rangle+\left\langle f \frac{\partial \bar{w}}{\partial z}\right\rangle+\frac{\partial^{2}}{\partial x_{\perp}^{2}}\left\langle\overline{u_{\|}^{\prime} u_{\perp}^{\prime}}\right\rangle,
\end{aligned}
$$

where angle brackets denote along-stream averages and $\mathbf{u}_{H}$ is the horizontal part of the velocity vector. Please note that the convergence of the EVF [last term on the right-hand side of Eq. (1)] simplifies when taking the along-stream average (e.g., Olbers et al. 2012). Furthermore, the DWBC is directed approximately southward so that the angle $\alpha$ between the zonal $(x)$ axis and the negative DWBC is close to $90^{\circ}$ and thus $|\sin \alpha|>|\cos \alpha|$. Given the fact that by definition, the alongstreamflow $\bar{u}_{\|}$is stronger than the across-streamflow $\bar{u}_{\perp}$, we assume the second term on the left-hand side of Eq. (2) to be much smaller than the first one. In other words, the acrossstream advection of planetary vorticity is negligible when compared with the along-stream advection. This yields

$$
\left\langle\beta \bar{u}_{\|} \sin \alpha\right\rangle=-\left\langle\overline{\mathbf{u}}_{H} \cdot \nabla_{H} \bar{\zeta}\right\rangle+\left\langle f \frac{\partial \bar{w}}{\partial z}\right\rangle+\frac{\partial^{2}}{\partial x_{\perp}^{2}}\left\langle\overline{u_{\|}^{\prime} u_{\perp}^{\prime}}\right\rangle .
$$

Because we are interested in what causes the DWBC slowdown, that is, the difference in the along-streamflow $\bar{u}_{\|}$between S1X and S2X, we formulate Eq. (3) for both scenarios and form their difference (hereinafter "S2X-S1X"):

$$
\underbrace{\beta \sin \alpha \Delta \bar{u}_{\|}}_{\text {I }}=\underbrace{-\Delta\left[\overline{\mathbf{u}}_{H} \cdot \nabla_{H} \bar{\zeta}\right]}_{\text {II }}+\underbrace{f \frac{\partial \Delta \bar{w}}{\partial z}}_{\text {III }}+\underbrace{\frac{\partial^{2}}{\partial x_{\perp}^{2}} \Delta\left[\overline{u_{\|}^{\prime} u_{\perp}^{\prime}}\right]}_{\text {IV }} .
$$

The symbol $\Delta$ denotes the difference of a quantity between $\mathrm{S} 2 \mathrm{X}$ and $\mathrm{S} 1 \mathrm{X}, \Delta[]=()_{\mathrm{S} 2 \mathrm{X}}-()_{\mathrm{S} 1 \mathrm{X}}$; it is an expression for the response to the wind stress doubling. Note that we omitted the angle brackets from the along-stream averaging. The resulting relation provides a possible link between the response in the advection of planetary vorticity [term I in Eq. (4)], which contains the response in the DWBC mean flow $\Delta \bar{u}_{\|}$, and the convergence of the EVF (term IV). For this link to be meaningful, the responses in the remaining terms, mean advection of relative vorticity (term II) and vortex stretching (term III), need to be small either because the respective terms are small in both S1X and S2X or because they are similar in S1X and $\mathrm{S} 2 \mathrm{X}$ and therefore their difference is negligible.

We show in Fig. 3 the terms from the response in the vorticity budget in the order in which they appear in Eq. (4). Term I depicts the response in the advection of planetary vorticity, i.e., the response in the DWBC mean flow multiplied by $\beta \sin \alpha$. The DWBC slowdown is reflected in the dominant positive (red) patch between about 100 and $250 \mathrm{~km}$ away from the continental shelf (the DWBC is going southward, and hence a slowdown shows up as $\Delta \bar{u}_{\|}>0$ ). Because we plot an average between $20^{\circ}$ and $5^{\circ} \mathrm{N}$, we expect the DWBC slowdown in the left panel in Fig. 3 (I) to be representative for most of the coherent part of the DWBC in the Northern Hemisphere that ranges from south of the Bahamas $\left(25^{\circ} \mathrm{N}\right)$ to the equator (e.g., Rhein et al. 2015; Buckley and Marshall 2016).

Among the three terms on the right-hand side of Eq. (4) (II-IV in Fig. 3), by far the best match for the response in the advection of planetary vorticity (term I) and hence the DWBC slowdown is the EVF convergence (term IV). It resembles the sign, shape, and magnitude of the response in the advection of planetary vorticity reasonably well in the depth range of the DWBC (between about 1000- and 4000-m depth). In contrast, 


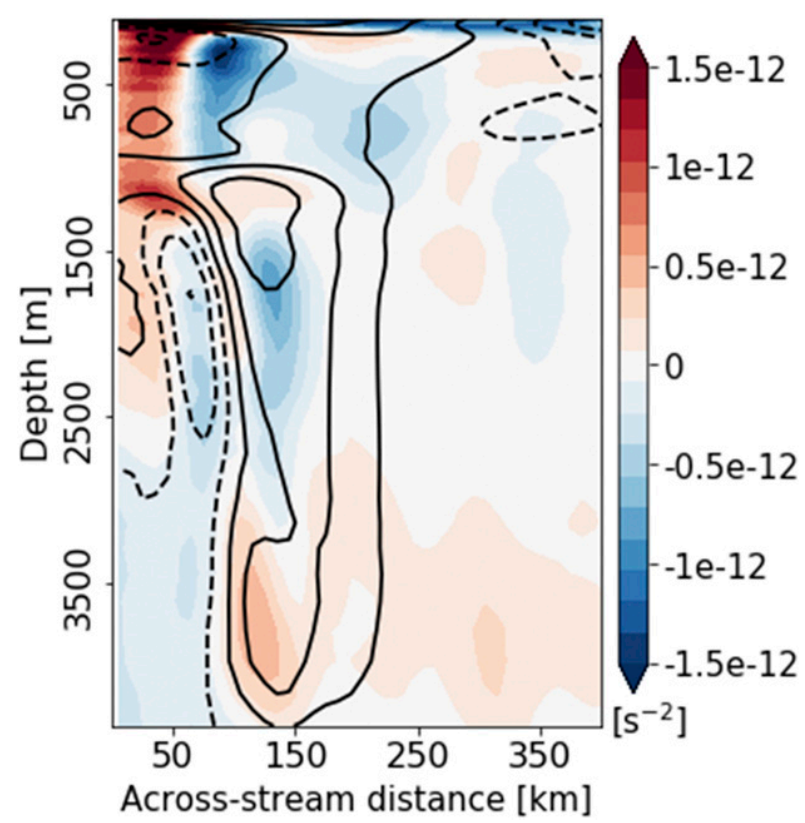

FIG. 4. Residual I-IV of the response S2X-S1X in the advection of planetary vorticity (I) and EVF convergence (IV) from Eq. (4). The two terms I and IV are also shown in Fig. 3. Black contour lines show the response in the advection of planetary vorticity, as in Fig. 3. The residual is of similar magnitude as terms II and III in Fig. 3 but is smaller than term I and IV, supporting the idea that the main balance in the response vorticity budget [Eq. (4)] is between the terms I and IV.

the magnitude and sign of the response in the vortex stretching (term III) does not match the response in the advection of planetary vorticity. Likewise, the response in the mean advection of relative vorticity (term II) is of smaller magnitude and with the wrong sign as compared with the advection of planetary vorticity response.

The residual I-IV of the advection of planetary vorticity and EVF convergence (Fig. 4) corroborates the close link between the two contributions in the DWBC response vorticity budget. The residual in the DWBC depth range is slightly weaker in magnitude than the remaining contributions II and III. In comparing the residual with term II, we see that the advection of relative vorticity by the mean flow helps to balance the response in the advection of planetary vorticity. However, the dominant balance in Eq. (4) is between terms I and IV:

$$
\beta \sin \alpha \Delta \bar{u}_{\|} \approx \frac{\partial^{2}}{\partial x_{\perp}^{2}} \Delta\left[\overline{u_{\|}^{\prime} u_{\perp}^{\prime}}\right]
$$

Because $\beta$ and $\sin \alpha$ are independent of the wind stress, we conclude that the DWBC slowdown in the STORM configuration, $\Delta \bar{u}_{\|}>0$, is primarily balanced by the EVF convergence. By providing an additional input of relative vorticity to the DWBC, eddies compensate for the reduction of planetary vorticity influx due to the slowdown of the DWBC mean flow.

In the coarse-resolution configuration GR15, eddy fluxes are in general very weak (von Storch et al. 2016), and thus the EVF convergence can be considered nonexistent. Furthermore, the
EVF consists of horizontal eddy momentum fluxes, which are also not captured by the Gent-McWilliams parameterization for mesoscale eddies (see also appendix A for a discussion of the role of the Gent-McWilliams parameterization on the response difference between STORM and GR15). The balance in Eq. (5) that we diagnosed from the eddying STORM configuration therefore provides an explanation for why the DWBC slows down in S2X but cannot slow down in G2X because here, the necessary balance by the EVF convergence is missing.

This work focuses on the response vorticity budget, in which the advection of planetary vorticity is largely balanced by the EVF convergence. However, we find that the latter also contributes significantly to the individual vorticity budgets of S1X and S2X, helping to balance the advection of planetary vorticity by the mostly southward directed DWBC [we show each term from the vorticity budget in the order in which they appear in Eq. (3) for S1X and for S2X in appendix C]. This in itself is a remarkable finding because, in the classic Stommel and Arons model of the abyssal circulation (Stommel and Arons 1959), planetary vorticity advection is balanced by the vortex stretching resulting from uniform upwelling in the interior $\left(f \partial w_{0} / \partial z \approx \beta v\right)$. In the western boundary region (i.e., in the DWBC), mainly boundary friction (e.g., Olbers et al. 2012) or the mean advection of relative vorticity (e.g., Edwards and Pedlosky 1998; Johnson et al. 2019) has been discussed as a candidate to balance the advection of planetary vorticity, while the EVF has been mostly ignored.

\section{b. Eddy thickness fluxes}

We have shown that the DWBC slowdown $\left(\Delta \bar{u}_{\|}>0\right)$, occurring as a response to a doubling of the surface wind stress, is directly related to the convergence of the EVF. But what about the second contribution in the eddy potential vorticity flux, the ETF (see introduction to section 4)? We said earlier that its magnitude is usually assumed to be larger than that of the EVF (Hogg 1983; Holland and Rhines 1980; Van Sebille et al. 2012).

Eliminating $\bar{w}$ between Eq. (3) and the time averaged density budget, which has been found to be reasonably approximated by $\overline{\mathbf{u}} \cdot \nabla \bar{\rho} \approx-\nabla \cdot \overline{\mathbf{u}^{\prime} \rho^{\prime}}$ near the DWBC (Lüschow et al. 2019 ), yields the along-stream averaged potential vorticity equation

$$
\begin{aligned}
& \left\langle\overline{\mathbf{u}}_{H} \cdot \nabla_{H}\left(\bar{\zeta}+f \frac{\partial \bar{\rho}}{\partial z}\right)\right\rangle+\left\langle\beta \bar{u}_{\|} \sin \alpha\right\rangle \\
& =-\frac{\partial}{\partial z}\left\langle f \frac{\nabla \cdot \overline{\mathbf{u}_{\perp}^{\prime} \rho^{\prime}}}{\partial \bar{\rho} / \partial z}\right\rangle+\frac{\partial}{\partial x_{\perp}}\left(\frac{\partial}{\partial x_{\perp}}\left\langle\overline{u_{\|}^{\prime} u_{\perp}^{\prime}}\right\rangle\right) .
\end{aligned}
$$

It allows a direct comparison of the ETF contribution (first term on the right-hand side) and the EVF convergence (second term on the right-hand side). The response S2X-S1X of the ETF contribution in Eq. (6), $\partial / \partial z \Delta\left[f \nabla \cdot \overline{\mathbf{u}_{\perp}^{\prime} \rho^{\prime}} / \partial \bar{\rho}\right]$, is shown in Fig. 5. Its magnitude is significantly smaller, and its spatial distribution does not resemble the response in the advection of planetary vorticity and hence the DWBC slowdown [Fig. 3, left panel (I)]. However, the vertically oriented dipole in the residual I-IV (positive between 1300 and $2700 \mathrm{~m}$ and negative below $2700 \mathrm{~m}$, Fig. 4) can also be found in the response of the 


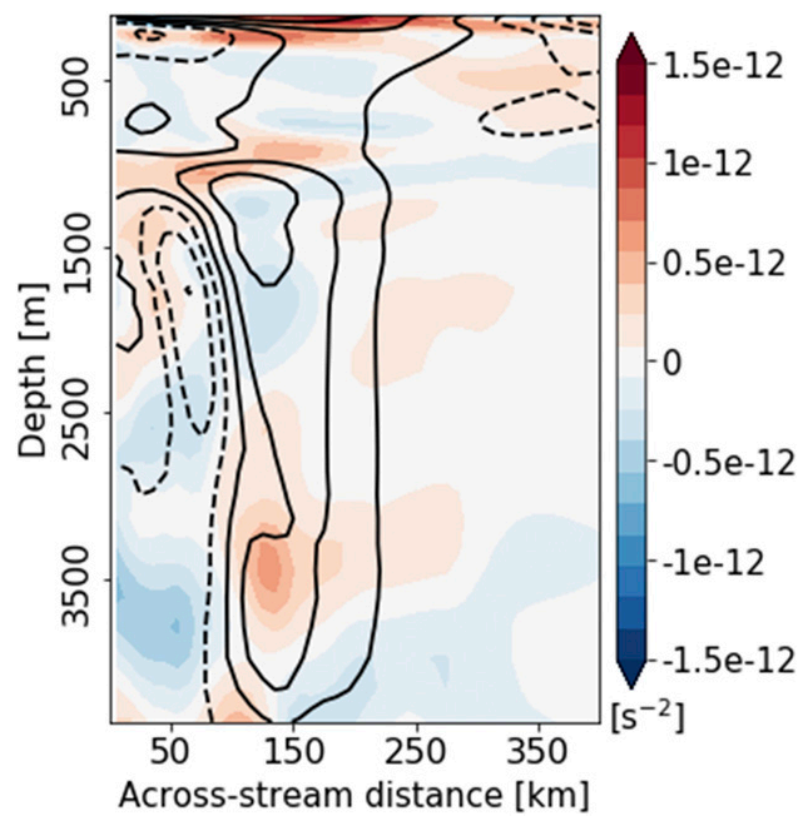

FIG. 5. Same depth-vs-across-stream view of the DWBC as in Fig. 3, but now we show in color shadings the response S2X-S1X in the ETF contribution, $\partial / \partial z \Delta\left[f \nabla \cdot \overline{\mathbf{u}_{\perp}^{\prime} \rho^{\prime}} / \partial \bar{\rho}\right]$. The ETF response cannot balance the response in the advection of planetary vorticity [Fig. 3, left panel (I)], but may help to balance the vertical dipole in the residual between the advection of planetary vorticity and the EVF convergence (I-IV; Fig. 4). Like before, the data are time averaged (2001-10) and averaged along the DWBC path $\left(20^{\circ}-5^{\circ} \mathrm{N}\right)$, and we apply a Gaussian filter in the across-stream direction with a half-width of $10 \mathrm{~km}$.

ETF contribution (Fig. 5). The ETF thus might be involved in setting the details of the vertical structure of the response. Yet, we conclude that compared to the EVF convergence, the ETF contribution plays a minor role for the DWBC slowdown.

This seems reasonable when considering the magnitude ratio $R$ of the EVF and ETF (the expression for the two fluxes can be found at the beginning of section 4 ),

$$
R=\frac{\frac{V^{\prime 2}}{\delta x}}{\frac{V^{\prime} \rho^{\prime} f}{\rho}}=\frac{V^{\prime}}{\rho^{\prime}} \frac{\rho}{\delta x f} .
$$

When going down in the water column, $R$ increases for strong and deep eddies because the eddy swirl speed $V^{\prime}$ stays more or less constant with depth (Lüschow et al. 2019) while variations in density $\rho^{\prime}$ decrease with depth like the surrounding stratification does. Thus, the relative importance of the EVF can be expected to increase with depth for vertically coherent eddies such as those in the DWBC (Lüschow et al. 2019).

\section{c. Causes of the DWBC slowdown}

The relation between the response in the advection of planetary vorticity (which reflects the DWBC slowdown) and the EVF convergence [Fig. 3, right panel (IV)] is an empirical statement about a balance. By itself, it does not answer the

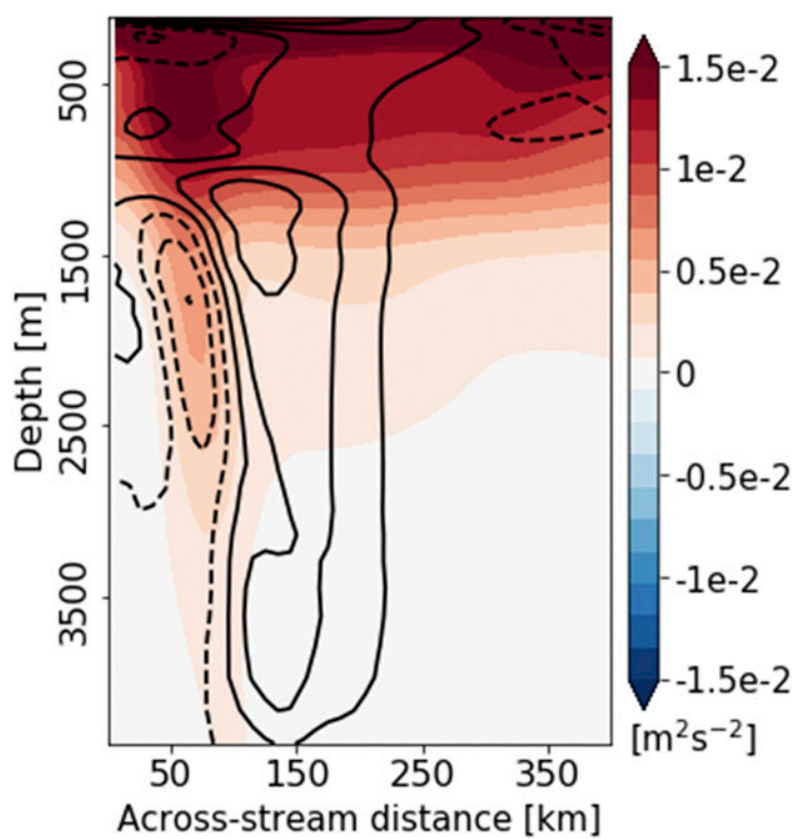

FIG. 6. Color shadings show the response S2X-S1X in EKE, black contours, again, show the response in the advection of planetary vorticity from Fig. 3 [left panel (I)]. The strongest increase in EKE occurs above $1000 \mathrm{~m}$ and therefore above the DWBC depth range. Yet, EKE near the DWBC also rises. Like before, the data are time averaged (2001-10) and averaged along the DWBC path $\left(20^{\circ}-5^{\circ} \mathrm{N}\right)$, and we apply a Gaussian filter in the across-stream direction with a half-width of $10 \mathrm{~km}$.

question whether the eddy fluxes play an active or passive role for the slowdown. With passive, we mean that eddies only react to a remotely caused DWBC slowdown by providing the vorticity input that is necessary to compensate for the change in the advection of planetary vorticity. With active on the other hand, we refer to a scenario in which the eddy field actively slows down the DWBC. If the eddies play an active role, the question arises what causes them to do so and hence what triggers the DWBC slowdown. This section and the following section provide arguments as to why we think that eddies might indeed play a rather active role for the DWBC slowdown and that the trigger is the response to the wind stress doubling in the northward mean flow above the DWBC.

The response of the EVF convergence is not confined to the depth range of the DWBC between 1000 and $4000 \mathrm{~m}$ but instead extends over the whole water column [Fig. 3, right panel (IV)]. Furthermore, the response in eddy kinetic energy (EKE) shows a strong increase not only in the upper ocean but also near the DWBC (see Fig. 6). In a DWBC that slows down, the generation of mesoscale eddies likewise declines. Hence, the increase in EKE near the DWBC implies that the additional EKE originates not in the DWBC but is generated nonlocally, most likely in the upper ocean northward flow. Both the response structure of EKE and EVF convergence suggest that changes of the DWBC eddy field originate not in the DWBC depth range but are caused above the DWBC where the northward branch of AMOC lies. 
At this point, we use the second sensitivity experiment, S2Xso, in which we double the wind stress only over the Southern Ocean. This experiment allows a distinction between remote and local effects of the wind stress doubling. In general, the DWBC slowdown in S2Xso has a similar structure and magnitude as that of S2X [cf. the black contour lines in Fig. 7 with that of the right panel in Fig. 3 (IV)]. This implies that both scenarios show a very similar response in their overturning streamfunctions (not shown). Only the maximum in the DWBC slowdown is slightly deeper in S2Xso as compared with S2X. Also, the response in the EVF convergence [term IV from (4)] is very similar in S2X and S2Xso [cf. the color shadings in Fig. 7 and the right panel in Fig. 3 (IV)]. This means that the Northern Hemisphere response in the eddy field near the DWBC, in particular in the EVF convergence, cannot be due to the doubling of the local Northern Hemisphere wind forcing. Instead, it must be caused by the wind stress doubling over the Southern Ocean. However, changes in the Northern Hemisphere eddy field need to be triggered by changes in the local Northern Hemisphere mean flow. In the next section, we investigate the response chronology and find evidence that a potential candidate for such a mean flow change is the strengthening of the northward surface flow occurring right before the DWBC transport declines.

\section{Time evolution of the response in the STORM runs S2X and S2Xso}

The top panel of Fig. 8 shows the response time series for the meridional transport at $13^{\circ} \mathrm{N}$. This latitude is one example within the domain studied; however, the qualitative behavior is similar everywhere between $5^{\circ}$ and $20^{\circ} \mathrm{N}$. Following Shakespeare and Hogg (2012), we split the transport into three layers: UPPER (northward) transport between 0- and 1000-m depth (Fig. 8), DWBC (southward) transport between 1000and 4000-m depth, and BOTTOM (northward) transport between $4000 \mathrm{~m}$ and the ocean bottom. Please note that the three quantities reflect the zonally averaged flow. In particular "DWBC" contains not only the flow in the DWBC. We chose this name because almost all of the response in the layer between 1000 and $4000 \mathrm{~m}$ happens in the actual DWBC.

The quasi-steady-state response of S2X was already discussed via the time-averaged overturning streamfunctions (Fig. 2); it emerges in its final form around 1995. The decrease in DWBC (Fig. 8) is linked to the strong decrease in BOTTOM and partly counteracted by a milder increase in UPPER. However, how does the wind induced signal propagate from the surface where the wind stress is doubled toward the deep ocean where the bottom overturning cell declines?

The most obvious propagation route would be via the Southern Ocean where the wind stress potentially affects the rate of $\mathrm{AABW}$ formation that feeds the bottom overturning (e.g., Brix and Gerdes 2003; Shakespeare and Hogg 2012; Poulsen et al. 2018; Rahmstorf and England 1997). However, previous studies expect the cross-equatorial propagation of AABW signals from the Southern Ocean toward the Northern Hemisphere to take at least a decade (e.g., Masuda et al. 2010; Zanowski and Hallberg 2017). In contrast, the S2X response at

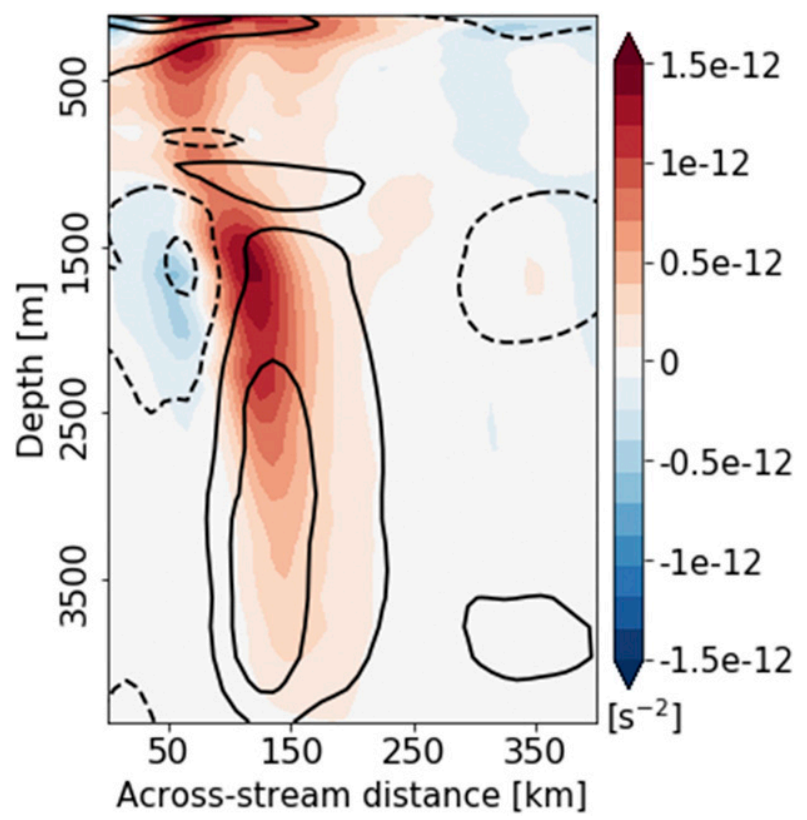

FIG. 7. As in the right panel of Fig. 3 (IV), but now we show the response to a wind stress doubling only over the Southern Ocean (S2Xso-S1X) in the EVF convergence [color shadings; term IV in Eq. (4)] and the advection of planetary vorticity containing the DWBC slowdown (black contour lines; term I). The response in the advection of planetary vorticity in general has a similar shape and magnitude as in the scenario with globally doubled wind stress [right panel in Fig. 3 (IV)] but with a deeper maximum. Like before, the EVF convergence is the main balance for the advection of planetary vorticity.

$13^{\circ} \mathrm{N}$ occurs after only 2 years in 1982 . This suggests that the response mechanism is rather local in the Northern Hemisphere. A potential trigger for this local response is the upper ocean northward transport: It shows a strong increase within a short time period (positive values of S2X-S1X in UPPER) right before BOTTOM and DWBC begin to decay. This increase in the northward mean flow right above the DWBC probably is responsible for the EKE increase near the DWBC (Fig. 6) and also the strong positive response in the EVF convergence [Fig. 3, right panel (IV)].

Again, it is informative to compare the responses of S2Xso (dashed lines in Fig. 8) and S2X (solid lines). Their quasisteady-state overturning response is similar, implying that on decadal time scale, the response is mainly controlled by the Southern Ocean wind stress. However, all of the time series in Fig. 8 show that the response in S2Xso is delayed by about 4 years as compared with S2X. Like in S2X, we note in S2Xso a short increase in UPPER right before BOTTOM and DWBC decline. If the abovementioned eddy-based interaction between the surface northward flow (UPPER) and the DWBC exists, it provides a potential explanation for the response delay in S2Xso. Because while in S2X, the initial peak in UPPER is caused by the local Northern Hemisphere wind stress doubling, UPPER at $13^{\circ} \mathrm{N}$ in S2Xso can increase only as a result of the remote effect of the Southern Ocean wind 

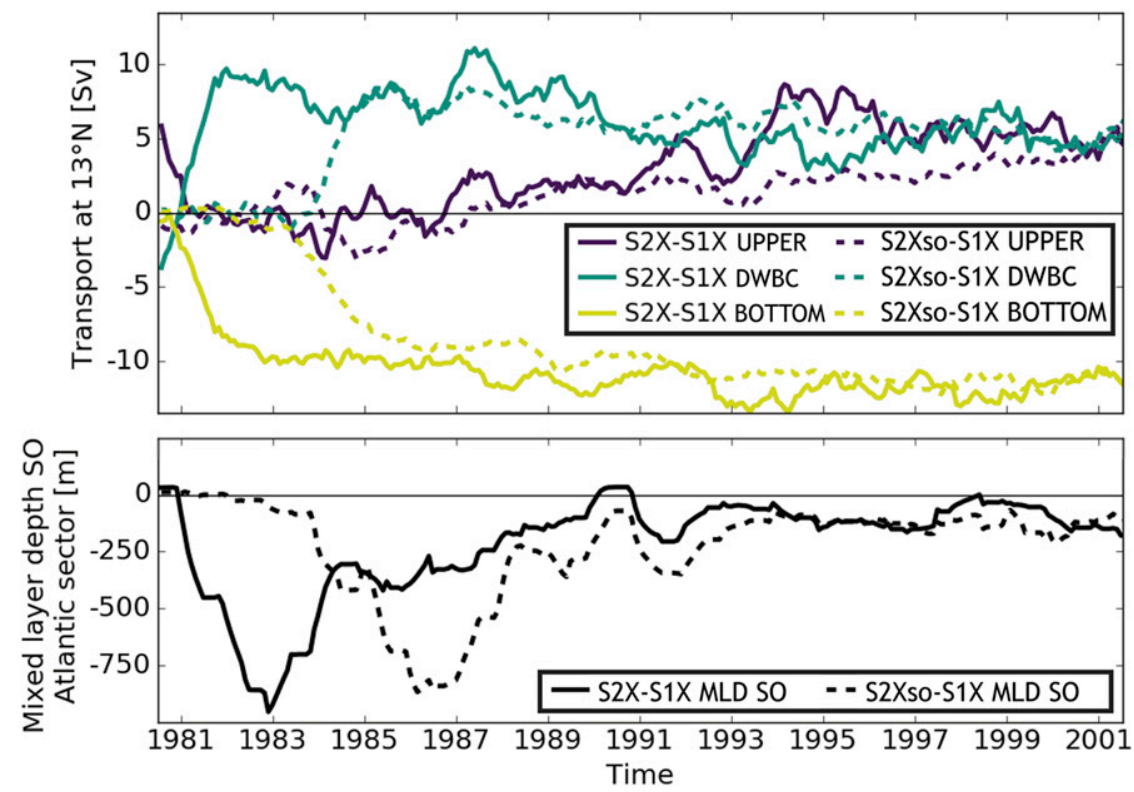

FIG. 8. The 12-months running mean response at $13^{\circ} \mathrm{N}$ of (top) total meridional transport between the surface and 1000-m depth ("UPPER"; purple), between 1000- and 4000-m depth (DWBC; turquoise), and between 4000- and 6000-m depth ("BOTTOM"; yellow) and (bottom) AABW formation indexed by the mixed layer depth in the Atlantic sector in the Southern Ocean, $50^{\circ}-17^{\circ} \mathrm{W}, 66^{\circ}-73^{\circ} \mathrm{S}$ (MLD SO; black). All solid lines refer to the response of the scenario with globally doubled wind stress, S2X-S1X. All dashed lines refer to the response of the scenario with the wind stress doubled only over the Southern Ocean, S2Xso-S1X. The wind stress doubling in S2X and S2Xso was executed in the year 1980.

stress doubling, that is, via the Drake Passage effect. This, however, happens on interannual to decadal time scales (e.g., Klinger and Cruz 2009) and thus serves as an explanation for the 4-year response delay of S2Xso.

One further piece of evidence comes from the time series of AABW formation shown in the lower panel of Fig. 8 (indexed by the mixed layer depth in the Atlantic sector of the Southern Ocean). Apparently, the amount of AABW formation decreases after the DWBC and BOTTOM cell transport at $13^{\circ} \mathrm{N}$ decline. Such an order of events is in contrast to previous studies that report perturbations in the AABW formation to precede changes in the bottom overturning cell (e.g., Purkey and Johnson 2012; Patara and Böning 2014).

In summary, we learn three things from the response chronology in Fig. 8 that suggest a new, local Northern Hemisphere response mechanism acting to slow down the DWBC via eddy fluxes:

1) A decline of the bottom overturning cell rooted in a reduction of $\mathrm{AABW}$ formation, as was used as an explanation in previous studies, can be ruled out. The bottom overturning declines before the AABW formation goes down. Furthermore, 2 years response time in S2X is not enough time for a signal induced in the Southern Ocean to travel to $13^{\circ} \mathrm{N}$.

2) In both $S 2 X$ and $S 2 X$ so, the rapid decline in the southward DWBC transport is preceded by a strengthening of the overlying northward transport. This strengthening leads to an intensification of the upper ocean eddy field that then also fuels the eddy field near the DWBC and thereby causes the response in the EVF convergence [Fig. 3, right panel (IV)], which then slows down the DWBC.

3) Such an interaction between the surface flow and the DWBC could explain the response delay in S2Xso: whereas the northward flow strengthens more or less immediately in $\mathrm{S} 2 \mathrm{X}$ as a result of the local impact of the Northern Hemisphere wind stress doubling, it takes a couple of years longer in S2Xso because here it happens via the Drake passage effect in the Southern Ocean.

\section{Summary and conclusions}

We analyze a set of wind sensitivity experiments in one eddying ("STORM"; $0.1^{\circ}$ resolution) and one non-eddying ("GR15"; $1.5^{\circ}$ resolution) configuration of the same realisticgeometry ocean model MPIOM.

\section{a. Differences in the quasi-steady-state response}

In both STORM and the GR15, the response is in principal agreement with the ocean seesaw concept; the upper (AMOC) cell strengthens whereas the bottom (AABW) cell weakens. Yet, the two configurations strongly disagree with regard to the magnitude of the bottom-cell response, which implies opposing responses in the deep western boundary current (DWBC, speedup in GR15 and slowdown in STORM). We provide 
strong evidence that the response differences are rooted in the fact that STORM explicitly resolves mesoscale eddies whereas GR 15 does not: between $5^{\circ}$ and $20^{\circ} \mathrm{N}$, eddy fluxes of relative vorticity essentially balance the DWBC slowdown in the time-averaged vorticity budget of STORM [right panel of Fig. 3 (IV) and section 4]. We conclude that without the explicit representation of eddies (as in GR15), the observed slowdown would be balanced differently and hence, is likely not to occur in non-eddying ocean models. Therefore, our vorticity budget analysis has implications for the ocean seesaw concept.

In the non-eddying GR15 experiments, both cells change by roughly the same magnitude, and this agrees with expectations inferred from previous non-eddying setups (e.g., Patara and Böning 2014). However, the DWBC slowdown in STORM, which we argue is dependent on resolved eddy fluxes, allows for larger differences in the response magnitude between upper and bottom cells. We interpret this as a decoupling of the two overturning cells and hence conclude that the seesaw effect might be weaker in the real (eddying) ocean than was observed in non-eddying ocean models.

\section{b. An eddy-based response mechanism}

In contrast to previous sensitivity experiments that find the bottom-cell response to be controlled by Southern Ocean processes, mainly changes in AABW formation (Brix and Gerdes 2003; Swingedouw et al. 2009; Patara and Böning 2014), the bottom-cell weakening in our eddying STORM configuration cannot be caused by the reduction of AABW formation because it happens before the AABW ceases. Also, the very fast bottom-cell response in the Northern Hemisphere conflicts with a remote (Southern Ocean induced) trigger for the bottom-cell response (see section 5).

Instead, we provide evidence that a local Northern Hemisphere interaction between the DWBC and the upperocean flow via mesoscale eddy fluxes causes the DWBC to slow down and in turn the bottom overturning cell to weaken. In this scenario, the interaction is triggered by a short strengthening of the surface flow right before the DWBC declines. This stronger surface flow leads to increased upper-ocean eddy activity and this also fuels the deep EKE (see Fig. 6). As a consequence of this full-depth eddy response, the response in the eddy vorticity flux (EVF) convergence likewise extends from the surface ocean down to 4000-m depth [Fig. 3 (right panel; IV) and Fig. 7]. In the DWBC depth range, the resulting excess input of relative vorticity by the EVF convergence is balanced by the advection of planetary vorticity, which implies that the DWBC mean flow has to slow down. Future research should further investigate this response mechanism, for example, by using an idealized layer model such as the one from Jayne et al. (1996) that was recently used by Le Bras et al. (2018) for a similar purpose.

\section{c. Conclusions}

The slowdown of the DWBC as response to a wind stress doubling is dependent on resolved mesoscale eddies and therefore can only occur in eddying but not in non-eddying ocean models. This indicates that the tight link between the upper and bottom overturning cells (ocean seesaw) might in part be an artifact of non-eddying ocean models; only with resolved eddies is it possible to capture the DWBC slowdown and hence to allow for the two cells to develop more independently. We suggest that the DWBC slowdown is activated through a response in the DWBC eddy field causing an excess input of relative vorticity to the DWBC. Via a reduction of the influx of planetary vorticity from the North-the slowdown of the DWBC mean flow-this excess input can be balanced. Not only is it noteworthy that, in general and also more specifically when compared with eddy fluxes of thickness, eddy vorticity fluxes seem to be crucial for the (deep) overturning response behavior. We also think that when interpreting the deep overturning response, we should in the future, in addition to looking for Southern Ocean processes, also consider the proposed new local response mechanism.

Acknowledgments. We thank Alexa Griesel and Achim Stössel for valuable discussions on the paper; Helmuth Haak, who supported us in all technical concerns; and Eileen Hertwig for carefully reading the draft paper. We are also grateful for comments by two anonymous reviewers. Furthermore, we acknowledge computing time granted by the German Climate Computing Center (DKRZ). This work was supported by the Max Planck Society and the International Max Planck Research School on Earth System Modelling. We also thank the German consortium project STORM, and especially the cluster of excellence CliSAP of the University Hamburg, for making the $0.1^{\circ}$ simulation possible. Data and scripts that were used for this paper can be obtained upon request.

\section{APPENDIX A}

\section{Dependence of the GR15 Response on the Gent-McWilliams Thickness Diffusivity}

The standard GR15 configuration of MPIOM (Jungclaus et al. 2006) uses a fairly low Gent-McWilliams thickness diffusivity $\kappa_{\mathrm{GM}}$ of $94 \mathrm{~m}^{2} \mathrm{~s}^{-1}$, as compared with other ocean models with similar resolution. Hence, in to rule out that this low value of $\kappa_{\mathrm{GM}}$ is responsible for the response difference between STORM and GR15, we perform two more sensitivity experiments in GR15: One with $\kappa_{\mathrm{GM}}=400 \mathrm{~m}^{2} \mathrm{~s}^{-1}$ and another one with $\kappa_{\mathrm{GM}}=1000 \mathrm{~m}^{2} \mathrm{~s}^{-1}$. The results are shown in Fig. A1, which depicts the response of the AMOC streamfunctions for the GR15 configuration using three different values of $\kappa_{\mathrm{GM}}$ as well as the response of the eddying STORM configuration. As compared with the response in STORM, the GR15 responses for the three different $\kappa_{\mathrm{GM}}$ show only minor differences. In particular, between about $0^{\circ}$ and $30^{\circ} \mathrm{N}$ we find a significantly stronger response in STORM than in all GR15 experiments. Stating that the dependence of the GR15-AMOC response on $\kappa_{\mathrm{GM}}$ is small as compared with the STORM response, we note that the AMOC itself in GR15 does depend on $\kappa_{\mathrm{GM}}$. As expected, AMOC weakens with increasing $\kappa_{\mathrm{GM}}$. This, however, is not the focus of this paper; more information on the $\kappa_{\mathrm{GM}}$ 


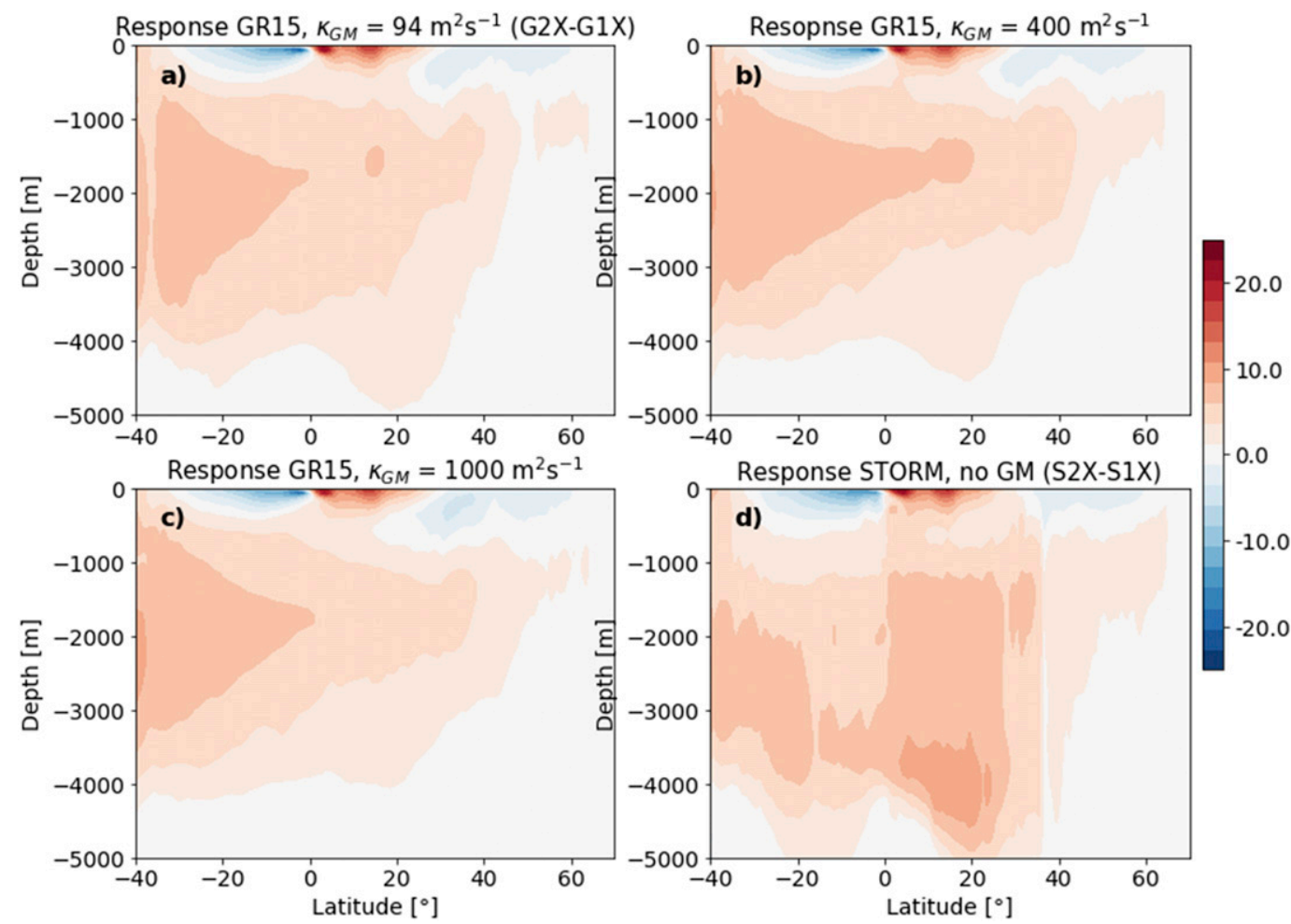

FIG. A1. Response of the AMOC to a wind stress doubling (2xWindstress-1xWindstress) for the noneddying GR15 configuration with three different Gent-McWilliams thickness diffusivities [(a) $\kappa_{\mathrm{GM}}=$ $94 \mathrm{~m}^{2} \mathrm{~s}^{-1}$ (this value of $\kappa_{\mathrm{GM}}$ was used in the main part of the paper), (b) $\kappa_{\mathrm{GM}}=400 \mathrm{~m}^{2} \mathrm{~s}^{-1}$, and (c) $\kappa_{\mathrm{GM}}=$ $1000 \mathrm{~m}^{2} \mathrm{~s}^{-1}$ ] as well as for (d) the eddying STORM configuration that uses no Gent-McWilliams parameterization. As above, all data are time averaged between 2001 and 2010. The AMOC response is similar for all GR15 simulations and thus is largely independent of the magnitude of $\kappa_{\mathrm{GM}}$, but it differs strongly in the eddying STORM configuration.

dependence of the GR15 configuration of MPIOM can be found in von Storch et al. (2016).

We use the Gent-McWilliams parameterization in its most basic form with spatially constant thickness diffusivity $\kappa_{\mathrm{GM}}$. Several more-sophisticated formulations are available (e.g., Visbeck et al. 1997; Eden and Greatbatch 2008), and it was reported that a spatially nonconstant $\kappa_{\mathrm{GM}}$ might improve the representation of the overturning response to different surface wind stresses (e.g., Viebahn and Eden 2010). However, we show in section 4 that the DWBC slowdown in STORM, which is the most obvious manifestation of the response difference between the eddying STORM and the noneddying GR15 configuration, is mostly balanced by horizontal eddy fluxes of relative vorticity (see Fig. 3). Those fluxes are not represented in the Gent-McWilliams eddy parameterization (Gent et al. 1995). Therefore, we assume that the response difference we find between STORM and GR15 is independent of the way in which Gent-McWilliams is implemented in GR15. Having shown that using different magnitudes of $\kappa_{\mathrm{GM}}$ does not bring the response of GR15 any closer to the response of STORM supports this assumption. On the basis of the previous discussion we think that using nonconstant $\kappa_{\mathrm{GM}}$ in GR15 would not produce a DWBC slowdown in the non-eddying GR15 configuration and thus would not remove the response difference between the eddying and the non-eddying configuration.

\section{APPENDIX B}

\section{Is the Analyzed Response Period Long Enough?}

In the above sensitivity experiments, we focus on the period from 2001 to 2010, corresponding to years 22-31 after the wind stress doubling in 1980. However, in particular the deep ocean needs up to several thousand years to fully equilibrate thermodynamically after a strong perturbation (e.g., Li et al. 2013). Thus, we cannot aim at understanding the equilibrium response to the wind stress doubling. Nonetheless, we consider our relatively short, decadal-scale experiments meaningful because (i) on Earth, the strengthening of the surface wind forcing is anticipated to happen on a decadal scale (Rintoul 2018), and so we think that studying the decadal-scale response of the ocean as part of the climate system is relevant in itself, and (ii) from an extension of the non-eddying GR15 sensitivity run by another 100 years, we find that indeed the largest part of the response in GR15 occurs within the first 30 years (see Fig. B1 for a time series of the overturning response). The strengthening of the upper overturning cell as well as the 


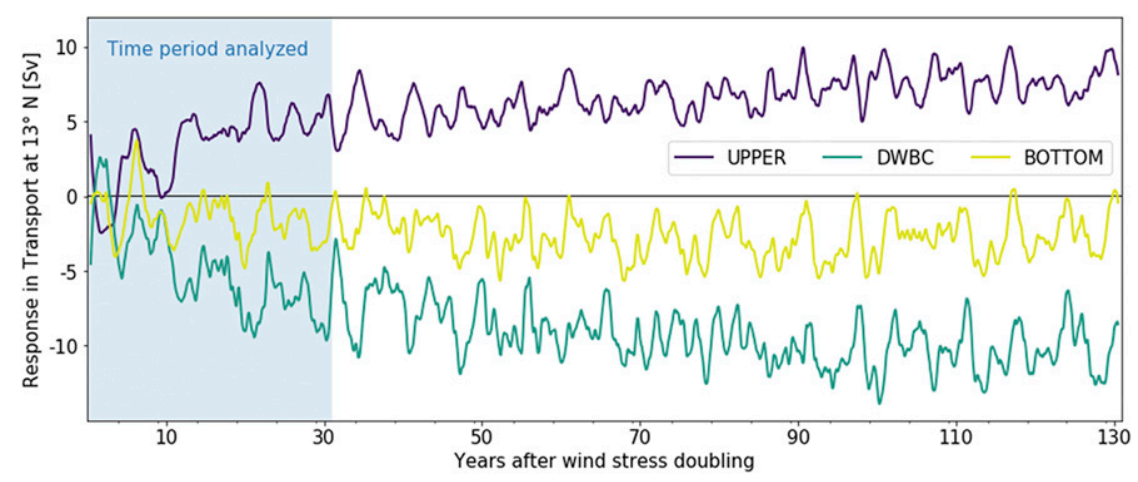

FIG. B1. Overturning response at $13^{\circ} \mathrm{N}$ of the non-eddying GR15: We show the response of the UPPER cell (purple), the DWBC (turquoise), and the BOTTOM cell (yellow) to a wind stress doubling. The blue-shaded region is the time period we analyze in the paper. Minor changes in the three overturning components occur outside the shaded region (after 2010); however, the overall response direction is largely set in the first 30 years after the wind stress doubling.

speed-up of the DWBC (a negative DWBC response indicates an increase in transport in the southward directed DWBC) do intensify outside the blue-shaded region, that is, outside the time period that we analyze in the paper. Yet, the largest part of the response obviously happens within the blue-shaded region, and thus our analysis is also valid for the centennial-scale response. This, of course, only applies to the non-eddying GR15 and cannot be directly transferred to the eddying STORM configuration. However, because signal propagation across the ocean is faster (and more realistic) in eddying models than in non-eddying models, we do not expect the response in STORM to be slower than in GR15. Thus, as in GR15, the main part of the centennial-scale response of STORM should lie within the period that we analyze above. Further support for the assumption that STORM has adjusted dynamically to a new quasi steady state under the doubled wind stress within the analyzed period is provided by the temporal evolution of EKE in the deep ocean; EKE strongly increases within the first 5 years after the forcing change and then quickly stabilizes at a higher level (not shown).

\section{APPENDIX C}

\section{Vorticity Budgets for S1X and S2X}

In the main text, we show only the differences S2X-S1X of the individual terms in the vorticity budget because we were interested in the DWBC slowdown $\Delta \bar{u}_{\|}=\bar{u}_{\|, \mathrm{S} 2 \mathrm{X}}-\bar{u}_{\|, \mathrm{S} 1 \mathrm{X}}$. The individual terms from Eq. (3) can be found in Fig. C1 for S1X
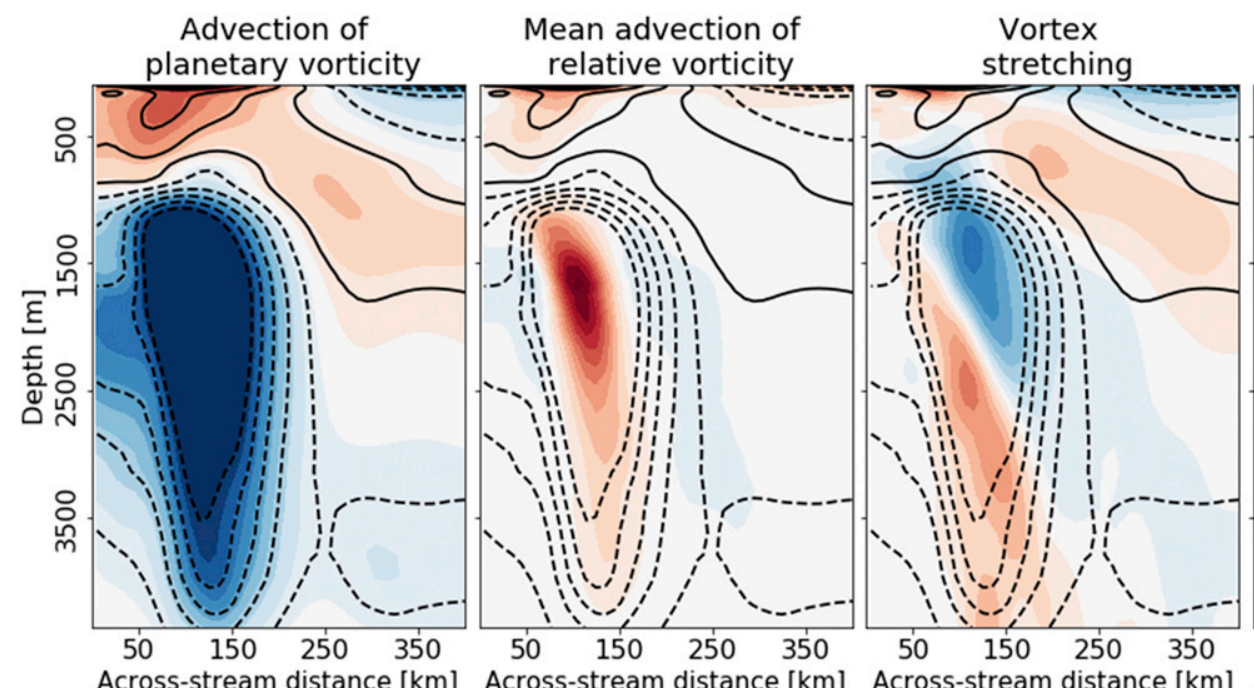

\section{Eddy vorticity flux convergence}

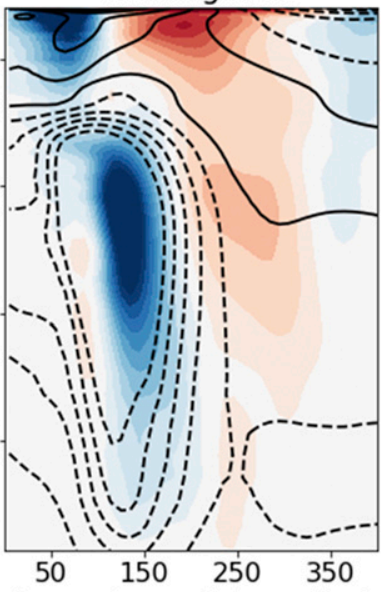

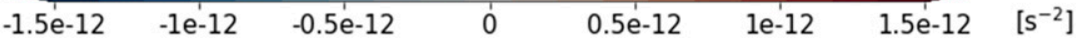

FIG. C1. Contributions to the DWBC vorticity budget for scenario $\mathrm{S} 1 \mathrm{X}$, averaged between $20^{\circ}$ and $5^{\circ} \mathrm{N}$, in the order in which they appear in Eq. (3). 

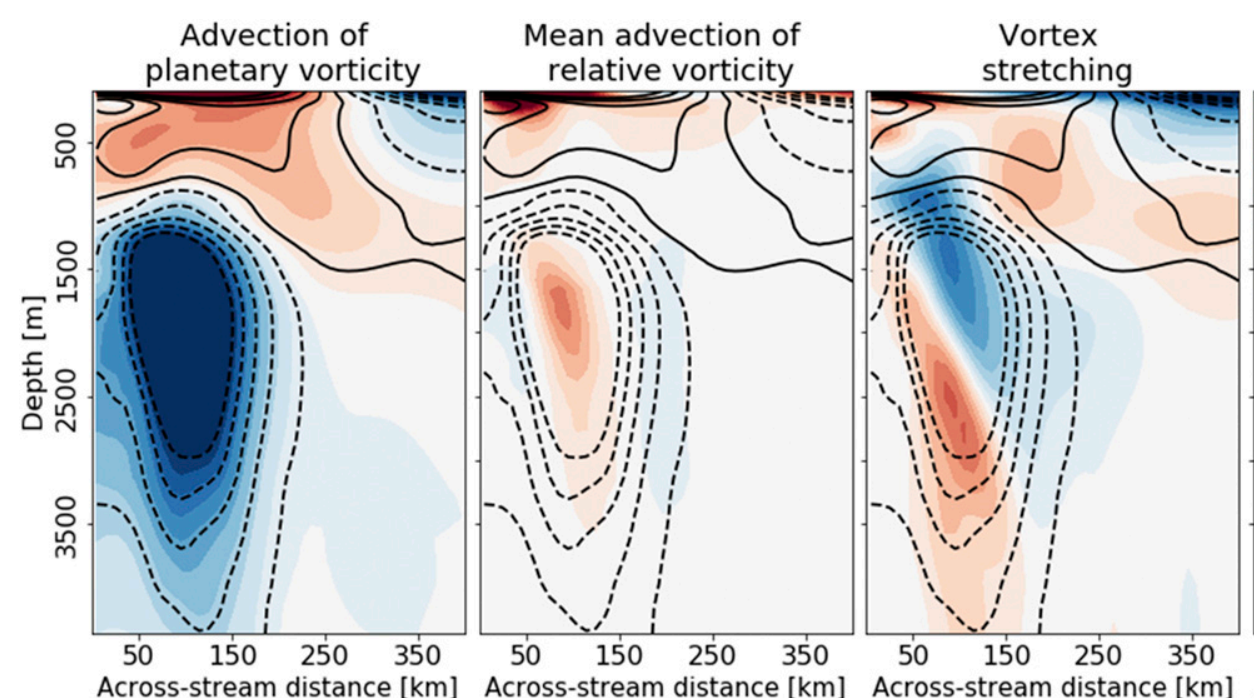

\section{Eddy vorticity flux convergence}

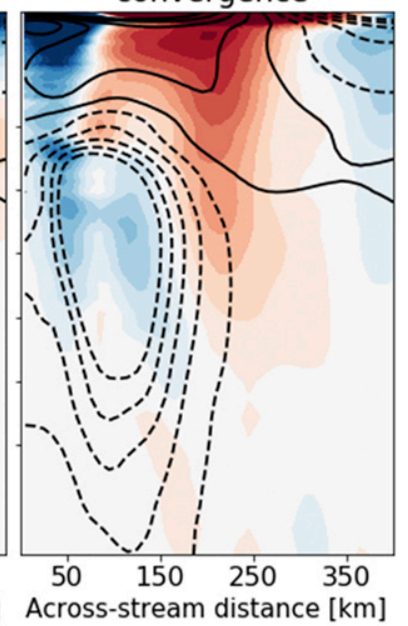

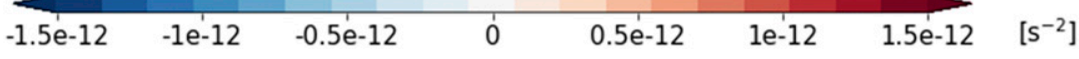

FIG. C2. As in Fig. C1, but for scenario S2X.

and in Fig. C2 for S2X in the order in which they appear in Eq. (3).

\section{REFERENCES}

Bishop, S. P., P. R. Gent, F. O. Bryan, A. F. Thompson, M. C. Long, and R. Abernathey, 2016: Southern Ocean overturning compensation in an eddy-resolving climate simulation. J. Phys. Oceanogr., 46, 1575-1592, https://doi.org/10.1175/JPO-D-150177.1.

Bracegirdle, T. J., E. Shuckburgh, J. B. Sallee, Z. Wang, A. J. Meijers, N. Bruneau, T. Phillips, and L. J. Wilcox, 2013: Assessment of surface winds over the Atlantic, Indian, and Pacific Ocean sectors of the Southern Ocean in CMPI5 models: Historical bias, forcing response, and state dependence. J. Geophys. Res. Atmos., 118, 547-562, https://doi.org/ 10.1002/jgrd.50153.

Brix, H., and R. Gerdes, 2003: North Atlantic Deep Water and Antarctic Bottom Water: Their interaction and influence on the variability of the global ocean circulation. J. Geophys. Res., 108, 3022, https://doi.org/10.1029/2002JC001335.

Broecker, W. S., 1998: Paleocean circulation during the last deglaciation: A bipolar seesaw? Paleoceanography, 13, 119-121, https://doi.org/10.1029/97PA03707.

Buckley, M. W., and J. Marshall, 2016: Observations, inferences, and mechanisms of the Atlantic Meridional Overturning Circulation: A review. Rev. Geophys., 54, 5-63, https://doi.org/ 10.1002/2015RG000493.

Eden, C., and R. J. Greatbatch, 2008: Towards a mesoscale eddy closure. Ocean Modell., 20, 223-239, https://doi.org/10.1016/ j.ocemod.2007.09.002.

Edwards, C., and J. Pedlosky, 1998: Dynamics of nonlinear crossequatorial flow. Part I: Potential vorticity transformation. J. Phys. Oceanogr., 28, 2382-2406, https://doi.org/10.1175/ 1520-0485(1998)028<2382:DONCEF>2.0.CO;2.

Farneti, R., and Coauthors, 2015: An assessment of Antarctic Circumpolar Current and Southern Ocean meridional overturning circulation during 1958-2007 in a suite of interannual
CORE-II simulations. Ocean Modell., 93, 84-120, https:// doi.org/10.1016/j.ocemod.2015.07.009.

Gent, P. R., 2016: Effects of Southern Hemisphere wind changes on the meridional overturning circulation in ocean models. Annu. Rev. Mar. Sci., 8, 79-94, https://doi.org/10.1146/annurev-marine122414-033929.

_ Parameterizing eddy-induced tracer transports in ocean circulation models. J. Phys. Oceanogr., 25, 463-474, https://doi.org/ 10.1175/1520-0485(1995)025<0463:PEITTI > 2.0.CO;2.

Gillett, N. P., and J. C. Fyfe, 2013: Annular mode changes in the CMIP5 simulations. Geophys. Res. Lett., 40, 1189-1193, https://doi.org/10.1002/grl.50249.

Hallberg, R., and A. Gnanadesikan, 2006: The role of eddies in determining the structure and response of the wind-driven southern hemisphere overturning: Results from the Modeling Eddies in the Southern Ocean (MESO) project. J. Phys. Oceanogr., 36, 2232-2252, https://doi.org/10.1175/JPO2980.1.

Henning, C. C., and G. K. Vallis, 2005: The effects of mesoscale eddies on the stratification and transport of an ocean with a circumpolar channel. J. Phys. Oceanogr., 35, 880-896, https:// doi.org/10.1175/JPO2727.1.

Hogg, A. M. C., P. Spence, O. A. Saenko, and S. M. Downes, 2017: The energetics of Southern Ocean upwelling. J. Phys. Oceanogr., 47, 135-153, https://doi.org/10.1175/JPO-D-16-0176.1.

Hogg, N. G., 1983: A note on the deep circulation of the western North Atlantic: Its nature and causes. Deep-Sea Res., 30A, 945-961, https://doi.org/10.1016/0198-0149(83)90050-X.

Holland, W. R., and P. B. Rhines, 1980: An example of eddy-induced ocean circulation. J. Phys. Oceanogr., 10, 1010-1031, https:// doi.org/10.1175/1520-0485(1980)010<1010:AEOEIO>2.0.CO;2.

Jayne, S. R., N. G. Hogg, and P. Malanotte-Rizzoli, 1996: Recirculation gyres forced by a beta-plane jet. J. Phys. Oceanogr., 26, 492-504, https://doi.org/10.1175/1520-0485(1996)026<0492: RGFBAB $>2.0 . C O ; 2$.

Johnson, H. L., P. Cessi, D. P. Marshall, F. Schloesser, and M. A. Spall, 2019: Recent contributions of theory to our understanding of the Atlantic Meridional Overturning Circulation. 
J. Geophys. Res. Oceans, 124, 5376-5399, https://doi.org/ 10.1029/2019JC015330.

Jungclaus, J. H., and Coauthors, 2006: Ocean circulation and tropical variability in the coupled model ECHAM5/MPI-OM. J. Climate, 19, 3952-3972, https://doi.org/10.1175/JCLI3827.1.

— and Coauthors, 2013: Characteristics of the ocean simulations in the Max Planck Institute Ocean Model (MPIOM) the ocean component of the MPI-Earth system model. J. Adv. Model. Earth Syst., 5, 422-446, https://doi.org/10.1002/jame.20023.

Kalnay, E., and Coauthors, 1996: The NCEP/NCAR 40-Year Reanalysis Project. Bull. Amer. Meteor. Soc., 77, 437-471, https:// doi.org/10.1175/1520-0477(1996)077<0437:TNYRP>2.0.CO;2.

Klinger, B. A., and C. Cruz, 2009: Decadal response of global circulation to Southern Ocean zonal wind stress perturbation. J. Phys. Oceanogr., 39, 1888-1904, https://doi.org/10.1175/ 2009JPO4070.1.

Le Bras, I. A., S. R. Jayne, and J. M. Toole, 2018: The interaction of recirculation gyres and a deep boundary current. J. Phys. Oceanogr., 48, 573-590, https://doi.org/10.1175/JPO-D-17-0206.1.

Li, C., J.-S. von Storch, and J. Marotzke, 2013: Deep-ocean heat uptake and equilibrium climate response. Climate Dyn., $\mathbf{4 0 ,}$ 1071-1086, https://doi.org/10.1007/s00382-012-1350-z.

Li, H., and J.-S. von Storch, 2013: On the fluctuating buoyancy fluxes simulated in a OGCM. J. Phys. Oceanogr., 43, 12701287, https://doi.org/10.1175/JPO-D-12-080.1.

Lüschow, V., J.-S. Von Storch, and J. Marotzke, 2019: Diagnosing the influence of mesoscale eddy fluxes on the deep western boundary current in the 1/10. J. Phys. Oceanogr., 49, 751-764, https://doi.org/10.1175/JPO-D-18-0103.1.

Marshall, G. J., 2003: Trends in the southern annular mode from observations and reanalyses. J. Climate, 16, 4134-4143, https:// doi.org/10.1175/1520-0442(2003)016<4134:TITSAM > 2.0.CO;2.

Marshall, J., and K. Speer, 2012: Closure of the meridional overturning circulation through Southern Ocean upwelling. Nat. Geosci., 5, 171-180, https://doi.org/10.1038/ngeo1391.

Marsland, S. J., H. Haak, J. H. Jungclaus, M. Latif, and F. Röske, 2003: The Max-Planck-Institute global ocean/sea ice model with orthogonal curvilinear coordinates. Ocean Modell., 5, 91127, https://doi.org/10.1016/S1463-5003(02)00015-X.

Masuda, S., and Coauthors, 2010: Simulated rapid warming of abyssal North Pacific waters. Science, 329, 319-322, https:// doi.org/10.1126/science.1188703.

Olbers, D., J. Willebrand, and C. Eden, 2012: Ocean Dynamics. Springer Science and Business Media, 703 pp.

Patara, L., and C. W. Böning, 2014: Abyssal ocean warming around Antarctica strengthens the Atlantic overturning circulation. Geophys. Res. Lett., 41, 3972-3978, https://doi.org/10.1002/ 2014GL059923.

Poulsen, M. B., M. Jochum, and R. Nuterman, 2018: Parameterized and resolved Southern Ocean eddy compensation. Ocean Modell., 124, 1-15, https://doi.org/10.1016/j.ocemod.2018.01.008.

Purkey, S. G., and G. C. Johnson, 2012: Global contraction of Antarctic Bottom Water between the 1980s and 2000s. J. Climate, 25, 5830-5844, https://doi.org/10.1175/JCLI-D-1100612.1.

Rahmstorf, S., and M. H. England, 1997: Influence of Southern Hemisphere winds on North Atlantic Deep Water flow. J. Phys. Oceanogr., 27, 2040-2054, https://doi.org/10.1175/ 1520-0485(1997)027<2040:IOSHWO>2.0.CO;2.

Rhein, M., D. Kieke, and R. Steinfeldt, 2015: Advection of North Atlantic Deep Water from the Labrador Sea to the southern hemisphere. J. Geophys. Res. Oceans, 120, 2471-2487, https:// doi.org/10.1002/2014JC010605.

Rhines, P. B., and W. R. Holland, 1979: A theoretical discussion of eddy-driven mean flows. Dyn. Atmos. Oceans, 3, 289-325, https://doi.org/10.1016/0377-0265(79)90015-0.

Rintoul, S. R., 2018: The global influence of localized dynamics in the Southern Ocean. Nature, 558, 209-218, https://doi.org/ 10.1038/s41586-018-0182-3.

Röske, F., 2006: A global heat and freshwater forcing dataset for ocean models. Ocean Modell., 11, 235-297, https://doi.org/ 10.1016/j.ocemod.2004.12.005.

Shakespeare, C. J., and A. M. Hogg, 2012: An analytical model of the response of the meridional overturning circulation to changes in wind and buoyancy forcing. J. Phys. Oceanogr., 42, 1270-1287, https://doi.org/10.1175/JPO-D-11-0198.1.

Spall, M. A., 1994: Wave-induced abyssal recirculations. J. Mar. Res., 52, 1051-1080, https://doi.org/10.1357/0022240943076830.

Stommel, H., and A. Arons, 1959: On the abyssal circulation of the world ocean - II. An idealized model of the circulation pattern and amplitude in oceanic basins. Deep-Sea Res., 6, 217-233, https://doi.org/10.1016/0146-6313(59)90075-9.

Swingedouw, D., T. Fichefet, H. Goosse, and M. F. Loutre, 2009: Impact of transient freshwater releases in the Southern Ocean on the AMOC and climate. Climate Dyn., 33, 365-381, https:// doi.org/10.1007/s00382-008-0496-1.

Thompson, D. W. J., and S. Solomon, 2002: Interpretation of recent Southern Hemisphere climate change. Science, 296, 895-899, https://doi.org/10.1126/science.1069270.

Toggweiler, J. R., and B. Samuels, 1995: Effect of Drake Passage on the global thermohaline circulation. Deep-Sea Res. I, 42, 477-500, https://doi.org/10.1016/0967-0637(95)00012-U.

__, and __, 1998: On the ocean's large-scale circulation near the limit of no vertical mixing. J. Phys. Oceanogr., 28, 1832-1852, https://doi.org/10.1175/1520-0485(1998)028<1832: OTOSLS $>2.0 . \mathrm{CO} ; 2$.

Van Sebille, E., W. E. Johns, and L. M. Beal, 2012: Does the vorticity flux from Agulhas rings control the zonal pathway of NADW across the South Atlantic? J. Geophys. Res., 117, C05037, https://doi.org/10.1029/2011JC007684.

Viebahn, J., and C. Eden, 2010: Towards the impact of eddies on the response of the Southern Ocean to climate change. Ocean Modell., 34, 150-165, https://doi.org/10.1016/j.ocemod. 2010.05.005.

Visbeck, M., J. Marshall, T. Haine, and M. Spall, 1997: Specification of eddy transfer coefficients in coarse-resolution ocean circulation models. J. Phys. Oceanogr., 27, 381-402, https://doi.org/10.1175/ 1520-0485(1997)027<0381:SOETCI >2.0.CO;2.

von Storch, J.-S., C. Eden, I. Fast, H. Haak, D. HernándezDeckers, E. Maier-Reimer, J. Marotzke, and D. Stammer, 2012: An estimate of the Lorenz energy cycle for the world ocean based on the STORM/NCEP simulation. J. Phys. Oceanogr., 42, 2185-2205, https://doi.org/10.1175/JPO-D-12079.1 .

-, H. Haak, E. Hertwig, and I. Fast, 2016: Vertical heat and salt fluxes due to resolved and parameterized meso-scale eddies. Ocean Modell., 108, 1-19, https://doi.org/10.1016/ j.ocemod.2016.10.001.

Zanowski, H., and R. Hallberg, 2017: Weddell Polynya transport mechanisms in the abyssal ocean. J. Phys. Oceanogr., 47, 29072925, https://doi.org/10.1175/JPO-D-17-0091.1. 